\title{
Eating Behaviour-Consumption Frequency of
} Certain Foods in Early Childhood as a Predictor of Behaviour Problems

\section{6-year follow-up study}

Ammara Ajmal, ${ }^{1}$ Kumi Watanabe, ${ }^{1}$ Emiko Tanaka, ${ }^{2}$ Yuko Sawada, ${ }^{3}$ Taeko Watanabe, ${ }^{4}$ Etsuko Tomisaki, ${ }^{5}$ Sumio Ito, ${ }^{6}$ Rika Okumura, ${ }^{6}$ Yuriko Kawasaki, ${ }^{6}$ Tokie Anme ${ }^{1}$

\begin{abstract}
Objectives: This study aimed to evaluate food consumption frequency in 1-6-year-olds as an eating behaviour-related predictor of behavioural problems over a span of six years. Eating behaviour in early childhood serves as a foundation for future health outcomes. Diet patterns can have long-term beneficial or adverse effects on social behaviour development. Methods: This longitudinal study was performed based on information obtained between July 2011 and August 2017 provided from a project named 'Community Empowerment and Care for Wellbeing and Health Longevity' initiated in 1991; the current study involved 124 mother-child dyads from the project. Children aged 1-6 years were studied in July 2011, with a follow-up assessment in August 2017. The primary exposure examined was the frequency of food items intake. The primary outcome was behaviour problems as assessed by the Strengths and Difficulties Questionnaire (SDQ). Results: The adjusted results suggested that a higher intake of leafy green and light-coloured vegetables were significantly associated with decreased odds of conduct problems and prosocial behaviour problems in Japanese children. However, no associations were observed among fruits, milk, small fish, eggs, soybeans, seaweed and any SDQ subscales. Conclusion: This study shows that eating leafy green and light-coloured vegetables may have a protective effect on a child's conduct and against prosocial behaviour problems. Due consideration should be given to children's eating habits in the early stages of their lives to ensure better mental health.
\end{abstract}

Keywords: Child; Diet; Impulsive behaviour; Longitudinal studies; Mental health; Nutrients; Sugars; Vegetables.
AdVANCES IN KNOWLEDGE
This study found that eating habits in early childhood can serve as a foundation for future behavioural development.
Adding leafy green and light-coloured vegetables in the diet at an early age can improve prosocial behaviour and prevent behaviour problems from developing later in life.

\section{Application to Patient Care}

Paediatricians, nutritionists and psychiatrists should encourage parents to add vegetables in children's diet at an early age to reap the beneficial effects on the child's mental health.

$\mathrm{E}$ ATING BEHAVIOUR IS ONE OF THE DETERminants of nutrient access and deficiency in early childhood. Food consumption frequency represents how often one consumes certain food items. ${ }^{1}$ It is evident from previous research that dietary habits acquired in childhood persist throughout life, and early childhood is crucial, as this is when particular dietary habits and sedentary behaviour patterns become established., ${ }^{2,3}$ Eating behaviour is a broad term; recent previous research focusing on the preferences of food items in early childhood reported differences in nutrient intake and unfavourable growth patterns in early childhood.4 Food consumption frequency during this developmental stage can have long-term effects on health and cause conditions such as coronary heart disease, diabetes and some cancers. ${ }^{5}$ Currently, there is a trend in the literature moving from the effects of specific nutrients to overall eating behaviour on mental health. Previous research has covered the beneficial effects of specific nutrients on cognition and behaviour. ${ }^{6}$ Furthermore, good dietary habits have been found to have positive effects on learning and attention and to reduce behavioural problems.?

Behaviour problems are becoming prevalent among children and many such children are unidentified and untreated. Early behavioural difficulties are associated with a higher risk of persistence later in life; thus, such early behaviour requires parental attention. ${ }^{8}$ One review found that there was a lack of evidence from short- 
term experimental studies for causality between dietespecially sugar intake-and behavioural problems. ${ }^{9}$ This review emphasised the need for future studies to explore the association between diet and hyperactivity during childhood. One previous study conducted on Korean children reported fewer learning, attention and behaviour problems among children with a higher consumption of dairy products and vegetables. ${ }^{7}$

Childhood is a pivotal period for the development of behaviour and cognition. Most previous studies have focussed on the associations between behaviour problems and infant breastfeeding duration or academic achievements. ${ }^{10,11}$ One of the domains about which these studies do not provide detailed information is the association between early eating habits in terms of food consumption frequency and behaviour problems in the early years of life. A healthy diet is related to better cognitive and behavioural function. ${ }^{12,13}$ Additionally, the consumption of a diet containing saccharides such as fruits and vegetables can improve the symptoms of attention deficit/hyperactivity disorder. ${ }^{13}$ Diets with low levels of micro-nutrients and higher polyunsaturated fatty acids were found to be associated with behavioural problems such as hyperactivity and aggression. ${ }^{11,14}$

In another study, children with behaviour problems have been reported to be from homes with poor family function. Low consumption of vegetables and fruits has also been reported among these families. Additionally, in this study, daughters of parents with psychological distress had lower consumption of fruits and vegetables than other children. ${ }^{15}$ Another review also reported that fathers' involvement in rearing children is associated with reduced behaviour problems. ${ }^{16}$

Dietary patterns in terms of food consumption frequency are known to vary among regions and most studies regarding dietary pattern and behavioural problems have been conducted in Western countries. Similar studies are needed to explore dietary patterns in Asian countries. Previous studies have been restricted to diets with a shortage of nutrients or food components. The concept of eating behaviour during childhood is an open research topic, especially regarding its effect on behavioural development. Furthermore, little evidence has been provided regarding the association between eating behaviour in early childhood and behaviour problems later in life. Therefore, the purpose of the study was to examine the association between eating behaviour, specifically food consumption frequency in children aged 1-6 years and their behaviour problems over a span of six years. It is hypothesised that eating behaviour in early childhood could predict behaviour problems in children later in their lives.

\section{Methods}

This study used the data from the 'Community Empowerment and Care for well-being and Health Longevity' (CEC) Cohort. The CEC is a longitudinal study that began in 1991 aiming to examine the factors associated with the well-being and health longevity of the residents of a suburban area in central Japan with approximately 5,000 residents. Questionnaires are distributed to all participants approximately every three years. The goal of the series of surveys was to provide information for creating health-promotion programmes to enhance the residents' quality of life. To avoid selection bias, this study utilised the questionnaire survey by introducing a complete sampling frame. The survey was conducted by the researchers in collaboration with the municipal government and local volunteers were assigned to distribute the questionnaires and collect them two weeks later to ensure that it was convenient for the residents to participate.

During the baseline year, 2011, 185 mothers with children aged 1-6 years responded to the survey. The data of six children from the baseline year were excluded due to the reporting of mental health issues. In the 6-year follow-up, 34 of the mothers who had previously participated were no longer available (due to having moved or other similar reasons) and 21 others were dropped due to having missing values in the Strengths and Difficulties Questionnaire (SDQ). Therefore, the 2017 data (the most recent year for which data was available) reported by 124 mothers, for whom there was no missing information, were included and analysed in the present study to examine the association between frequency of food consumption and children's behaviour problems.

The authors assessed children's behaviour problems utilising the parent-reported Japanese version of the SDQ. ${ }^{17}$ The SDQ is a brief behavioural screening tool incorporating 25 items divided equally among five subscales; 1) conduct problems (e.g. the child often loses his/her temper); 2) emotional symptoms (e.g. the child has many worries or often seems worried); 3) hyperactivity/inattention (e.g. the child is restless, overactive and cannot sit still for long); 4) peer relationship problems (e.g. the child is rather solitary or prefers to play alone); and 5) prosocial behaviour (positive behaviours, e.g. the child is considerate of other people's feelings). Each item is scored using a three-point Likert scale $(0=$ not true, $1=$ somewhat true and 2 = certainly true). Scores for each item are summed to calculate subscale scores ranging from 0 to 10. Subscale scores for conduct problems, emotional symptoms, hyperactivity/inattention and 
peer relationship problems are used to calculate a total difficulties score (the sum of 20 items), ranging from 0 to 40, and a prosocial behaviour score ranging from 0 to 10 . The score for prosocial behaviour is not incorporated in the total difficulty score, as prosocial behaviour is conceptually different from psychological problems. A higher total difficulty score indicates a higher risk of development of subsequent subscale behaviour problems. In contrast, higher scores in prosocial behaviour indicate a lower risk of developing prosocial behaviour problems.

Continuous SDQ scores are meaningful in epidemiological data and suitable for longitudinal studies, as they are sensitive to changes in children. ${ }^{18,19}$ However, the authors categorised them into 'normal' and 'risk' groups based on the Japanese standard SDQ scores (a 20\% cut-off measured from the negative region of the spectrum). Risk groups were defined by scores of 4-10 points for the conduct problems, emotional symptoms and peer relationship problems scales; 6-10 points for the hyperactivity scale; and 13-40 points for total difficulty. ${ }^{20}$ For the prosocial behaviour scale, scores of $0-5$ points indicate those at risk..$^{20}$ The parent-reported version of the SDQ is as efficient as a semi-structured interview technique and evidence has been provided for strong psychometric properties across several countries. ${ }^{18,21}$ The reliability of the Japanese version of SDQ has been previously assessed, with reports showing the internal consistency coefficients (Cronbach's alpha) for the five subscales ranging from $0.52-0.69$ and 0.77 for the total difficulty measurement. ${ }^{20}$

Eating behaviour was measured using motherreported items about children's eating frequency per week for different food items at baseline. Mothers were asked 'How often does your child eat the following per week?: leafy green vegetables (e.g. spinach), lightcoloured vegetables (e.g. cabbage), fruits, soybeans and soy products (e.g. tofu), milk and dairy products, eggs, fish and seaweed. Mothers responded using a four-point Likert scale ( $1=$ little, $2=1-2$ times per week, 3 = 3-4 times per week, 4 = nearly every day). The response alternatives were dichotomised into frequent consumption patterns and rare (infrequent) consumption patterns. Consuming a food item 3-4 times per week or more constituted frequent consumption and $0-2$ times per week constituted rare consumption. ${ }^{22}$ The quantity of food intake was not recorded; only the frequency of consumption was recorded for the different food items.

The authors collected data from mothers regarding demographic characteristics (i.e. age, gender, family structure and siblings), health information (i.e. any acute illness, having a paediatrician and sleep pattern) and parental care (i.e. mother's stress, father's support and parent-child interaction). Demographic characteristics such as age (date of birth), gender ( 1 = boy and 2 = girl), family structure (dichotomised as living with father and mother as a nuclear family vs living with parents and grandparents as an extended family), siblings $(1=$ yes and $2=$ no), health information (e.g. acute illness; 1 = yes and $2=$ no), sleep condition (dichotomised into sufficient sleep if 'always' and insufficient sleep if 'sometimes' or 'not much'; reported by respondents as 1 = yes always, $2=$ sometimes and $3=$ not much), having a paediatrician ( $1=$ yes and 2 $=$ no), parental information such as mother's stress (dichotomised into always vs sometimes if response was sometimes, rarely or very little), father support (dichotomised into always proactive vs sometimes if response was 'sometimes' or 'reluctant') and parental interaction (dichotomised into every day if response was 'always' and 'a few times' a week if response was '3-4' times/week, '1-2' times/week, or 'rarely'). The authors chose these variables because they represented factors that could confound the relationship between eating habits and social-emotional development.

The main exposure was eating leafy green vegetables, light-coloured vegetables, fruits, soybeans and soy products, milk and dairy products, eggs, fish and seaweed. Outcomes were conduct problems, emotional symptoms, hyperactivity/inattention and the scores of the peer relationship problems subscale, prosocial behaviour scale and total difficulty. There were three phases in the present analysis. In the first phase, descriptive statistics were defined using frequencies. In the second phase, Fischer's exact test was used for the bivariate analysis to examine related factors with five aspects of the SDQ and total difficulty score. In the third phase, a multiple logistic regression model was used for a multivariable analysis and to explore the association between eating habits and socialemotional development. Only those factors meeting statistical significance in the Fischer's exact test were included in the regression model. Out of the total six outcomes, conduct problems and prosocial behaviour were based on the result of Fischer's exact test. Two exposures were used in each logistic regression model: leafy green vegetables and light-coloured vegetables. The authors adjusted the regression models for demographic characteristics, health information and parental care; both SDQ subscales were added separately. The analysis was carried out using SAS (university edition; SAS Institute, Cary, NC, USA). Statistical significance was set to $P<0.05$.

Ethics approval for the CEC was provided by the ethics committee of the University of Tsukuba (13311). All participants provided written consent before participation. 


\section{Results}

In total, data of 124 children aged 1-6 years were used in the study; this sample comprised of 67 (54.0\%) boys and 57 (46.0\%) girls. Of the participants, 99 (79.8\%) had siblings and 83 (66.9\%) lived with their extended families. In addition, 59 (47.6\%) mothers in the dyads were stressed and only 30 (24.2\%) fathers supported mothers in childcare [Table 1].

Regarding the other demographic characteristics (i.e. age, family type, siblings, sleep and father's support), association with behaviour problems was not evident in the present study. Regarding the bivariate association of participant's characteristics and behaviour problems, conduct behaviour risk in children was significantly associated with mother's stress $(P=0.02)$, acute illness $(P=0.04)$ and having a paediatrician $(P=0.03)$. Prosocial behaviour was found to be significantly associated with gender $(P=0.01)$ and parent-child interaction $(P<0.01)$ [Table 2].

Regarding the consumption frequency of milk, fruits, soybean and soy products, eggs, small fish and seaweed, no significant association was revealed in the bivariate analysis. The bivariate analysis between the food consumption frequency and behaviour problems revealed a significant association between conduct behaviour and the frequency of consumption of leafy green $(P<0.01)$ and light-coloured vegetables $(P<0.01)$. Additionally, the authors also found a significant association between prosocial behaviour and frequency of consumption of leafy green $(P<0.01)$ and light-coloured vegetables $(P<0.01)$ [Table 3 ].

Logistic regression was conducted for the two outcomes that showed significant results in the bivariate analysis. Table 4 and Table 5 show the multivariable regression analysis results of both unadjusted and adjusted models (adjusted for age, gender, family type, siblings, any acute illness, having a paediatrician, sleep pattern, mother's stress, father's support and parent-child interaction) for the conduct problems and prosocial behaviour problems subscales. The multivariable regression analysis showed that children with frequent consumption of leafy green vegetables had 0.12 -fold lower odds of conduct behaviour problem and 0.23-fold lower odds of prosocial behaviour problems than children consuming leafy green vegetables rarely. Additionally, children with frequent consumption of light-coloured vegetables have 0.19-fold lower odds of conduct behaviour problem and 0.19-fold lower odds of prosocial behaviour problems than children consuming these vegetables rarely.

There was strong evidence for associations among frequent consumption of leafy green vegetables, light-coloured vegetables and the SDQ subscales (conduct problems and prosocial behaviour). Children frequently consuming leafy green and light-coloured vegetables showed a decreased risk of conduct and prosocial behaviour problems, both before and after adjustment. There were no associations between other food groups and any SDQ subscales.

\section{Discussion}

This study examined the association between eating habits in early childhood (1-6 years old) and behaviour problems over the span of six years in a sample of

Table 1: Participant demographics at the baseline year of the study, $2011(\mathrm{~N}=124)$

\begin{tabular}{|c|c|c|}
\hline Items & $\mathbf{n}$ & Rate in percent \\
\hline \multicolumn{3}{|l|}{ Age in years } \\
\hline $1-3$ & 63 & 50.8 \\
\hline $4-6$ & 61 & 49.2 \\
\hline \multicolumn{3}{|l|}{ Gender } \\
\hline Boys & 67 & 54.0 \\
\hline Girls & 57 & 46.0 \\
\hline \multicolumn{3}{|l|}{ Family type } \\
\hline Nuclear family & 41 & 33.1 \\
\hline Extended family & 83 & 66.9 \\
\hline \multicolumn{3}{|l|}{ Siblings } \\
\hline No & 25 & 20.2 \\
\hline Yes & 99 & 79.8 \\
\hline \multicolumn{3}{|l|}{ Acute illness } \\
\hline Yes & 13 & 10.5 \\
\hline No & 111 & 89.5 \\
\hline \multicolumn{3}{|l|}{ Enough sleep } \\
\hline Always & 108 & 87.1 \\
\hline Sometimes & 16 & 12.9 \\
\hline \multicolumn{3}{|c|}{ Having a paediatrician } \\
\hline Yes & 83 & 66.9 \\
\hline No & 41 & 33.1 \\
\hline \multicolumn{3}{|l|}{ Mother's stress } \\
\hline Yes & 59 & 47.6 \\
\hline No & 65 & 52.4 \\
\hline \multicolumn{3}{|l|}{ Father's support } \\
\hline Yes & 30 & 24.2 \\
\hline No & 94 & 75.8 \\
\hline \multicolumn{3}{|c|}{ Parent-child interaction } \\
\hline Everyday & 91 & 73.4 \\
\hline Few times a week & 33 & 26.6 \\
\hline
\end{tabular}


Table 2: Associations between demographic characteristics and behaviour problems six years later $(\mathrm{N}=124)$

\begin{tabular}{|c|c|c|c|c|c|c|c|c|}
\hline \multirow{3}{*}{$\begin{array}{l}\text { Demographic } \\
\text { variables }\end{array}$} & \multirow[t]{3}{*}{ Category } & \multirow[t]{3}{*}{ Total } & \multirow{2}{*}{\multicolumn{2}{|c|}{$\begin{array}{c}\text { Conduct problem } \\
\text { n (\%) }\end{array}$}} & \multicolumn{4}{|c|}{ Prosocial behaviour } \\
\hline & & & & & \multirow[t]{2}{*}{$P$ value* } & \multicolumn{2}{|c|}{ n (\%) } & \multirow[t]{2}{*}{$P$ value* } \\
\hline & & & $\begin{array}{l}\text { Normal } \\
\text { group }\end{array}$ & Risk group & & $\begin{array}{l}\text { Normal } \\
\text { group }\end{array}$ & Risk group & \\
\hline \multirow[t]{2}{*}{ Gender } & Boys & 67 & $43(64.2)$ & $24(35.8)$ & \multirow[t]{2}{*}{0.14} & $30(44.8)$ & $37(55.2)$ & \multirow[t]{2}{*}{0.01} \\
\hline & Girls & 57 & $35(61.4)$ & $22(38.6)$ & & $36(63.2)$ & $21(36.8)$ & \\
\hline \multirow[t]{2}{*}{ Acute illness } & Yes & 13 & $5(38.5)$ & $8(61.5)$ & \multirow[t]{2}{*}{0.04} & $9(69.2)$ & $4(30.8)$ & \multirow[t]{2}{*}{0.11} \\
\hline & No & 111 & $73(65.8)$ & $38(34.2)$ & & $57(51.4)$ & $54(48.6)$ & \\
\hline \multirow{2}{*}{$\begin{array}{l}\text { Having a } \\
\text { paediatrician }\end{array}$} & Yes & 83 & 47 (56.6) & $36(43.4)$ & \multirow[t]{2}{*}{0.03} & $41(49.4)$ & $42(50.6)$ & \multirow[t]{2}{*}{0.07} \\
\hline & No & 41 & $31(75.6)$ & $10(24.4)$ & & $25(61.0)$ & $16(39.0)$ & \\
\hline \multirow[t]{2}{*}{ Mother's stress } & Yes & 59 & $32(54.2)$ & $27(45.8)$ & \multirow[t]{2}{*}{0.02} & $32(54.2)$ & $27(45.8)$ & \multirow[t]{2}{*}{0.13} \\
\hline & No & 65 & $46(70.8)$ & $19(29.2)$ & & $34 .(52.3)$ & $31(47.7)$ & \\
\hline \multirow{2}{*}{$\begin{array}{l}\text { Parent-child } \\
\text { interaction }\end{array}$} & Everyday & 91 & $60(65.9)$ & $31(34.1)$ & \multirow[t]{2}{*}{0.08} & $56(61.5)$ & $35(38.5)$ & \multirow[t]{2}{*}{$<0.01$} \\
\hline & $\begin{array}{c}\text { Few times a } \\
\text { week }\end{array}$ & 33 & $18(54.5)$ & $15(45.5)$ & & $10(30.3)$ & $23(69.7)$ & \\
\hline
\end{tabular}

"Results determine using Fischer's exact test. P values of $<0.05$ were considered significant.

Table 3: Association between food consumption frequency and behaviour problems six years later

\begin{tabular}{|c|c|c|c|c|c|c|c|}
\hline \multirow[t]{3}{*}{ Food items } & \multirow[t]{3}{*}{ Category } & \multirow[t]{3}{*}{ Total } & \multicolumn{2}{|c|}{ Conduct problems } & \multicolumn{2}{|c|}{ Prosocial behaviour } & \multirow[t]{3}{*}{$P$ value } \\
\hline & & & \multicolumn{4}{|c|}{ n (\%) } & \\
\hline & & & Normal group & Risk group & Normal group & Risk group & \\
\hline \multirow[t]{2}{*}{ Leafy vegetables } & Frequently & 102 & $72(70.6)$ & $30(29.4)$ & $63(61.7)$ & $42(41.2)$ & \multirow[t]{2}{*}{$<0.01$} \\
\hline & Rare & 22 & $6(27.2)$ & $16(72.7)$ & $6(27.3)$ & $16(72.7)$ & \\
\hline \multirow{2}{*}{$\begin{array}{l}\text { Light-coloured } \\
\text { vegetables }\end{array}$} & Frequently & 105 & $72(68.6)$ & $33(31.4)$ & $62(59.1)$ & $43(40.9)$ & \multirow[t]{2}{*}{$<0.01$} \\
\hline & Rare & 19 & $6(31.6)$ & 13 (68.4) & $4(21.1)$ & 15 (78.9) & \\
\hline
\end{tabular}

"Results of Fischer's exact test. P-values of $<0.05$ were considered significant.

Table 4: Results of multiple logistic regression showing the odds of conduct problems with relation to eating vegetables

\begin{tabular}{|c|c|c|c|c|c|c|}
\hline \multirow[t]{2}{*}{ Food items } & \multicolumn{2}{|c|}{ Unadjusted OR } & \multirow[t]{2}{*}{$P$ value } & \multicolumn{2}{|c|}{ Adjusted OR* } & \multirow[t]{2}{*}{$P$ value } \\
\hline & OR & $95 \%$ CI & & OR & $95 \% \mathrm{CI}$ & \\
\hline $\begin{array}{l}\text { Leafy green } \\
\text { vegetables }\end{array}$ & 0.15 & $0.05-0.43$ & $<0.001$ & 0.12 & $0.04-0.41$ & $<0.001$ \\
\hline $\begin{array}{l}\text { Light-coloured } \\
\text { vegetables }\end{array}$ & 0.21 & $0.07-0.61$ & $<0.001$ & 0.19 & $0.06-0.61$ & 0.005 \\
\hline
\end{tabular}

$O R=$ odds ratio; $C I=$ confidence interval.

*Adjusted for demographic characteristics (age, gender, family type and siblings), health information (any acute illness, having a paediatrician, and sleep pattern), and parental care (mother's stress, father's support and parent-child interaction).

Table 5: Results of multiple logistic regression showing the odds of prosocial behaviour problems with relation to eating vegetables

\begin{tabular}{|c|c|c|c|c|c|c|}
\hline \multirow[t]{2}{*}{ Food items } & \multicolumn{2}{|c|}{ Unadjusted OR } & \multirow[t]{2}{*}{$P$ value } & \multicolumn{2}{|c|}{ Adjusted OR* } & \multirow[t]{2}{*}{$P$ value } \\
\hline & OR & $95 \%$ CI & & OR & $95 \% \mathrm{CI}$ & \\
\hline $\begin{array}{l}\text { Leafy green } \\
\text { vegetables }\end{array}$ & 0.26 & $0.09-0.72$ & 0.01 & 0.23 & $0.07-0.74$ & 0.01 \\
\hline $\begin{array}{l}\text { Light-coloured } \\
\text { vegetables }\end{array}$ & 0.18 & $0.05-0.59$ & $<0.01$ & 0.19 & $0.05-0.69$ & 0.01 \\
\hline
\end{tabular}

$O R=$ odds ratio; $C I=$ confidence interval.

*Adjusted for demographic characteristics (age, gender, family type and siblings), Health information (any acute illness, having a paediatrician, and sleep pattern) and parental care (mother's stress, father's support and parent-child interaction). 
children from a suburban area in central Japan. The hypothesis that eating behaviour in early childhood would be associated with behaviour problems was partially supported. Of the different food groups, only leafy green vegetables and light-coloured vegetables were associated with factors of behavioural development, such as problems with conduct and prosocial behaviour. The results showed that children who frequently consumed leafy green vegetables and light-coloured vegetables in the early years of their lives showed lower odds for conduct and prosocial behaviour problems. To the best of the authors' knowledge, this relationship has not been shown previously in studies on early childhood from Japan.

Few studies have explored the relationship between behavioural development and food consumption frequency in early childhood. A recent Australian study showed that children who had behavioural problems, lower prosocial behaviours and were from poorly functioning household, consumed fewer fruits and vegetables. ${ }^{15}$ This is consistent with the results of the present study regarding vegetable intake. However, in the present study, no association was found between fruit intake and behaviour problems.

This study sought to examine the effects early childhood eating behaviours have on social behaviour development, filling a gap in the literature from previous research, which focussed on adolescents. ${ }^{22}$ Peacock et al. demonstrated that a 'junk pattern' and non-milk extrinsic sugar are associated with total difficulty scores and low prosocial behaviour scores. ${ }^{23}$ However, these associations were attenuated substantially following adjustment. In this study, the authors did not observe any associations between any food items and total difficulty scores. Fish intake is associated with omega-3 fatty acids and an early study in Japan and a later review showed that having a high number of behaviour problems is associated with low total omega- 3 fatty acid intake. ${ }^{24,25,26}$ However, a study conducted in Australia found no association between fatty acids and attention-deficit/hyperactivity disorder symptoms. ${ }^{27}$ Furthermore, a randomised controlled trial showed no improvement in children with aggression and disruptive behaviour with fish oil treatment. ${ }^{28}$ The authors can relate these findings to the results of the present study, in that the authors did not find any association between a low intake of fish and behaviour problems. This result could have occurred because the age group measured at baseline was 1-6 years and the frequency of fish intake was lower in the present study's total sample than it would be with older participants.
This study reports findings demonstrating a significant association between vegetable intake and behaviour problems in childhood. The mechanism behind this relationship is not yet clear; however, a possible mechanism may be connected to the function of dopamine in maintaining attention and controlling impulsive behaviour. ${ }^{29}$ Vitamins $\mathrm{B} 6$ and $\mathrm{C}$ act as coenzymes involved in the production of dopamine and vegetables are a source of Vitamin B6 and vitamin C. ${ }^{12}$ The primary strength of this study was the collection of detailed data from a large prospective cohort in central Japan. The collection of data on chronic disease status during the baseline year helped exclude children with a mental illness. Moreover, it enabled the investigation of 'new cases' of behavioural problems. In addition, the wealth of data collected throughout the cohort permitted the authors to adjust for several potential confounders.

A potential limitation of this study was that only one suburban community from central Japan was included in the study; therefore, a more comprehensive geographical survey should be conducted to generalise the results. The authors utilised parentally completed SDQ scores, which could have led to parents underestimating behavioural problems, which would have decreased the likelihood of associations with other food items. Another limitation is that several potential factors that previous studies noted to be associated with behaviour problems, such as the family's socioeconomic status, parents' educational level and the mother's well-being were not included in the questionnaire. The authors aimed to clarify which food item consumed at the baseline year is associated with behaviour development; therefore, the authors did not assess eating behaviour as a time-varying covariate. Further detailed investigations are required to explore changes in eating behaviour and behaviour development.

It is possible that using food frequency questionnaires to determine underlying eating behaviour may not be an appropriate method for this particular outcome. Using a quantitative analysis for each food item could have provided further associations. However, a validation study showed that a food frequency questionnaire could identify those with high and low food intake and showed a moderate capability for ranking individuals by food intake. $^{30}$ Neurodevelopmental disorders, such as conduct disorders, are moderately heritable with different genetic factors; however, it was out of scope for the present study. In the future, genetic factors and biological and environmental factors should be considered together to explore the causality. 


\section{Conclusion}

Keeping the aforementioned admonition in mind, the findings of the present study are consistent with those showing associations between diet and mental health, offering evidence indicating that a diet rich in vegetables could prevent behaviour problems in children. Given the considerable pressure of increasing behaviour problems in children, determining whether the introduction of vegetables in the diet could prevent behaviour problems is of principal public health importance. More research is warranted to examine this relationship. Future studies should also incorporate some interventional studies to determine whether dietary habits could prevent or improve behaviour problems in children.

\section{CONFLICT OF INTEREST}

The authors declare no conflicts of interest.

\section{FUNDING}

This study was funded by Grants-in-Aid for Scientific Research (17H02604).

\section{AUTHORS' CONTRIBUTION}

AA conceptualised the study, synthesised the analysis plan, managed and analysed the data, interpreted findings and led the writing of the manuscript. KW was responsible for study coordination, data collection, and subsequent revisions. EtT, YS, TW, EmT, SI, RO, and YK contributed to data collection. TA is the principal investigator on the project and assisted in the revisions of the manuscript. All authors approved the final version of the manuscript.

\section{References}

1. Gomez P, Schneid N, Delaere F. How often should I eat it? Product correlates and accuracy of estimation of appropriate food consumption frequency. Food Qual Prefer 2015; 40:1-7. https://doi.org/10.1016/j.foodqual.2014.07.018.

2. Movassagh EZ, Baxter-Jones ADG, Kontulainen S, Whiting SJ, Vatanparast $\mathrm{H}$. Tracking dietary patterns over 20 years from childhood through adolescence into young adulthood: The Saskatchewan Pediatric Bone Mineral Accrual Study. Nutrients 2017; 9:990. https://doi.org/10.3390/nu9090990.

3. Reilly JJ. Physical activity, sedentary behaviour and energy balance in the preschool child: Opportunities for early obesity prevention. Proc Nutr Soc 2008; 67:317-25. https://doi.org/10.1017/S002 9665108008604

4. Kwon KM, Shim JE, Kang M, Paik H-Y. Association between picky eating behaviors and nutritional status in early childhood: Performance of a picky eating behavior questionnaire. Nutrients 2017; 9:463. https://doi.org/10.3390/nu9050463.

5. World Health Organization. Diet, Nutrition, and the Prevention of Chronic Diseases Report of a Joint WHO/FAO Expert Consultation. Geneva, Switzerland: World Health Organization, 2003. WHO TRS 916.
6. Spencer JPE. The impact of fruit flavonoids on memory and cognition. Br J Nutr 2010; 104:S40-7. https://doi.org/10.1017/ S0007114510003934

7. Park S, Cho S-C, Hong Y-C, Oh S-Y, Kim J-W, Shin M-S, et al. Association between dietary behaviors and attention-deficit/ hyperactivity disorder and learning disabilities in schoolaged children. Psychiatry Res 2012; 198:468-76. https://doi. org/10.1016/j.psychres.2012.02.012.

8. Treyvaud K, Doyle LW, Lee KJ, Roberts G, Lim J, Inder TE, et al. Social-emotional difficulties in very preterm and term 2 year olds predict specific social-emotional problems at the age of 5 years. J Pediatr Psychol 2012; 37:779-85. https://doi. org/10.1093/jpepsy/jss042.

9. Bellisle F. Effects of diet on behaviour and cognition in children. Br J Nutr 2004; 92:S227-32. https://doi.org/10.1079/ BJN20041171.

10. Belfort MB, Rifas-Shiman SL, Kleinman KP, Bellinger DC, Harris $\mathrm{MH}$, Taveras EM, et al. Infant breastfeeding duration and mid-childhood executive function, behavior, and socialemotional development. J Dev Behav Pediatr 2016; 37:43-52. https://doi.org/10.1097/DBP.0000000000000237.

11. Hinshaw SP. Externalizing behavior problems and academic underachievement in childhood and adolescence: Causal relationships and underlying mechanisms. Psychol Bull 1992; 111:127-55. https://doi.org/10.1037/0033-2909.111.1.127.

12. Kim JY, Kang SW. Relationships between dietary intake and cognitive function in healthy Korean children and adolescents. J Lifestyle Med 2017; 7:10-17. https://doi.org/10.15280/jlm.2 017.7.1.10.

13. Dykman KD, Dykman RA. Effect of nutritional supplements on attentional-deficit hyperactivity disorder. Integr Physiol Behav Sci 1998; 33:49-60. https://doi.org/10.1007/BF02688675.

14. Benton D. The influence of dietary status on the cognitive performance of children. Mol Nutr Food Res 2010; 54:457-70. https://doi.org/10.1002/mnfr.200900158.

15. Renzaho AMN, Kumanyika S, Tucker KL. Family functioning, parental psychological distress, child behavioural problems, socioeconomic disadvantage and fruit and vegetable consumption among 4-12 year-old Victorians, Australia. Health Promot Int 2011; 26:263-75. https://doi.org/10.1093/heapro/daq054.

16. Jorosi-Tsiamo WB, Mogobe KD, Mokotedi MT. Male involvement in child care activities: a review of the literature in Botswana. Afr J Reprod Health 2013; 17:35-42.

17. Goodman R, Scott S. Comparing the Strengths and Difficulties Questionnaire and the Child Behavior Checklist: Is small beautiful? J Abnorm Child Psychol 1999; 27:17-24. https://doi. org/10.1023/a:1022658222914.

18. Goodman A, Goodman R. Strengths and Difficulties Questionnaire as a dimensional measure of child mental health. J Am Acad Child Adolesc Psychiatry 2009; 48:400-3. https://doi. org/10.1097/CHI.0b013e3181985068.

19. Ford T, Collishaw S, Meltzer H, Goodman R. A prospective study of childhood psychopathology: Independent predictors of change over three years. Soc Psychiatry Psychiatr Epidemiol 2007; 42:953-61. https://doi.org/10.1007/s00127-007-0272-2.

20. Matsuishi T, Nagano M, Araki Y, Tanaka Y, Iwasaki M, Yamashita Y, et al. Scale properties of the Japanese version of the Strengths and Difficulties Questionnaire (SDQ): A study of infant and school children in community samples. Brain Dev 2008; 30:410-5. https://doi.org/10.1016/j.braindev.2007.12.003.

21. Stone LL, Otten R, Engels RCME, Vermulst AA, Janssens JMAM. Psychometric properties of the parent and teacher versions of the Strengths and Difficulties Questionnaire for 4to 12-year-olds: A review. Clin Child Fam Psychol Rev 2010; 13:254-74. https://doi.org/10.1007/s10567-010-0071-2.

22. Øverby N, Høigaard R. Diet and behavioral problems at school in Norwegian adolescents. Food Nutr Res 2012; 56:17231. https://doi.org/10.3402/fnr.v56i0.17231. 
23. Peacock PJ, Lewis G, Northstone K, Wiles NJ. Childhood diet and behavioural problems: Results from the ALSPAC cohort. Eur J Clin Nutr 2011; 65:720-6. https://doi.org/10.1038/ejcn. 2011.27.

24. Itomura M, Hamazaki K, Sawazaki S, Kobayashi M, Terasawa K, Watanabe S, et al. The effect of fish oil on physical aggression in schoolchildren - a randomized, double-blind, placebo-controlled trial. J Nutr Biochem 2005; 16:163-71. https://doi.org/10.1016/j. jnutbio.2004.10.009.

25. Hamazaki T, Hamazaki K. Fish oils and aggression or hostility. Prog Lipid Res 2008; 47:221-32. https://doi.org/10.1016/j. plipres.2008.02.001.

26. Raine A, Portnoy J, Liu J, Mahoomed T, Hibbeln JR. Reduction in behavior problems with omega-3 supplementation in children aged 8-16 years: A randomized, double-blind, placebo-controlled, stratified, parallel-group trial. J Child Psychol Psychiatry 2015; 56:509-20. https://doi.org/10.1111/jcpp.12314.
27. Ng K-H, Meyer BJ, Reece L, Sinn N. Dietary PUFA intakes in children with attention-deficit/hyperactivity disorder symptoms. Br J Nutr 2009; 102:1635-41. https://doi.org/10.1017/S00071145 09990821.

28. Dean AJ, Bor W, Adam K, Bowling FG, Bellgrove MA. A randomized, controlled, crossover trial of fish oil treatment for impulsive aggression in children and adolescents with disruptive behavior disorders. J Child Adolesc Psychopharmacol 2014; 24:140-8. https://doi.org/10.1089/cap.2013.0093.

29. Bisht AT, Kukreti VT. Role of micronutrients on children with attention deficit hyperactivity disorder: A contentious issue. Indian J Public Health Res Dev 2014; 5:90. https://doi.org/10.59 58/0976-5506.2014.00019.9.

30. Lillegaard ITL, Øverby N, Andersen L. Evaluation of a short food frequency questionnaire used among Norwegian children. Food Nutr Res 2012; 56:6399. https://doi.org/10.3402/fnr. v56i0.6399. 